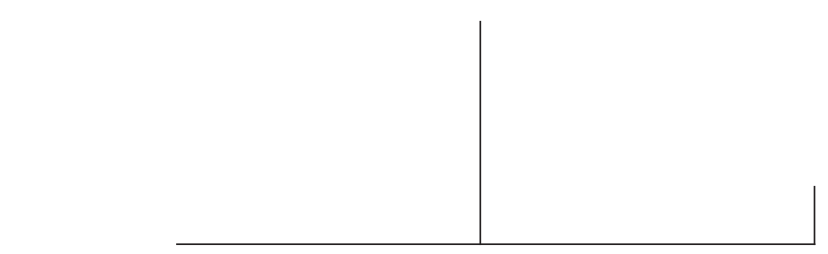

Rev. Latinoam. Psicopat. Fund., III, 1, 143-157

\title{
Paixões de transferência
}

\author{
Rubens Marcelo Volich
}

Este trabalho tem por objetivo iniciar a reflexão sobre a função da transferência como operadora incontornável da apreensão e da compreensão da doença, em seu sentido mais amplo, e da psicopatologia em particular. Mais que um "dispositivo" da técnica psicanalítica, a transferência se constitui como verdadeiro paradigma da experiência que revela a imbricação inevitável do sofrimento de dois seres em relação. É a elaboração desta experiência que permite a constituição do conhecimento psicopatológico.

Destaca-se aqui como, muito antes da formulação deste conceito, a sensibilidade de Freud à sua experiência transferencial, com relação aos seus objetos de estudo e a suas relações pessoais e profissionais, constituiu-se como um vetor determinante de seu percurso da neurologia à psicanálise, uma dimensão pouco considerada na história da psicanálise bem como na do próprio conceito de transferência. A elaboração dessa experiência foi um operador fundamental que permitiu a Freud compreender e efetuar as teorizações e transformações que instrumentaram sua passagem da pesquisa neuro-fisiológica e da clínica médica clássica ao desenvolvimento da psicanálise, enquanto método terapêutico e corpo teórico.

Palavras-chave: Transferência, técnica psicanalítica, história da psicanálise, hipnose 


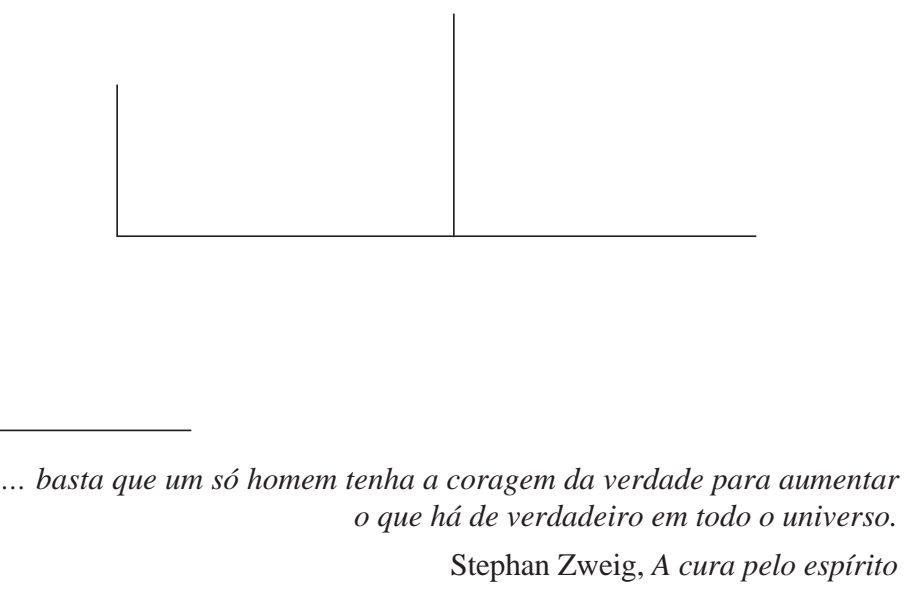

Quando de uma visita aos Estados Unidos, em 1926, S. Ferenczi foi desafiado por John Watson, representante da nascente escola comportamental, a um duelo intelectual. Watson afirmava ser absolutamente inútil o recurso à introspecção para a compreensão dos processos psíquicos, uma vez que seria suficiente para tanto descrever a atividade e o comportamento dos seres vivos, animais ou humanos, considerando-os como conjuntos de reflexos e tropismos. Ele exemplificou sua teoria descrevendo o reflexo de terror, observado tanto em um camundongo como em um bebê, desencadeado por um ruído inesperado. Ferenczi retrucou respondendo que para concluir que foi terror o que motivou o reflexo de fuga, Watson deveria certamente ter se referido àquilo que ele mesmo, experimentador, sentia na mesma situação. A partir da auto-observação, mesmo sem se dar conta, ele teria deduzido a possibilidade de fazer comparações entre suas próprias experiências e as reações que observara. "O behaviorista é apenas um explorador disfarçado do psiquismo", conclui Ferenczi, mordaz. ${ }^{1}$

Por meio dessa frase incisiva, Ferenczi faz cair por terra a máscara da suposta objetividade na compreensão dos fenômenos humanos, evidenciando um recalque incrustrado na cultura. Se máscaras existem, não temos como negá-lo, são elas as míticas máscaras da tragédia grega, do trágico e do cômico, que não deixam de oferecer àqueles que as contemplam o enigma instigante do desvendamento dos rostos

1. S. Ferenczi. "Le processus de la formation psychanalytique" (1928), in Psychanalyse IV, Euvres complètes 1927-1933. Paris: Payot, 1982, p. 240. 


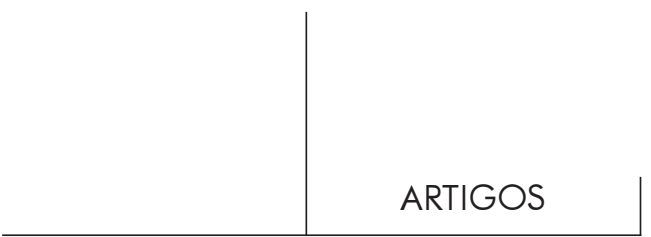

que se escondem por detrás de tais paixões. Máscaras-enigmas, máscarasinterpretações que impõem às trocas humanas o estranho terror-prazer, irrecusável, das brincadeiras infantis de esconde-esconde.

Seres conceituais, pouco sabemos dos sentidos que nos governam. Nossas idéias, antes de tudo, foram carne e sangue, gestadas em seres que, como nós, deambulam por esse mundo imersos em suas paixões. Paixões de transferência que, antes mesmo de nosso vir-ao-mundo, determinam desejos que nos transformam em história.

\section{Grandes homens}

Tudo começou muito cedo. Com oito anos, Shakespeare. Desde sempre, Jacob. Sobretudo uma lembrança deste que, em sua juventude, foi intimado por um cristão a descer da calçada para recolher seu chapéu-de-peles, jogado na lama por ser ele judeu. Desde então, o conflito: entre os ideais e a realidade, entre a miséria e a grandeza, entre a vitimização e o heroísmo, entre a melancolia e a euforia. Crescer. Conhecer. Cultivar dentro de si a literatura, a mitologia, a história e seus heróis Aníbal, Moisés, Goethe, Schiller, Homero, Virgílio e o próprio Shakespeare - que passam a fazer parte das cenas interiores e dos sonhos dos quais o jovem Sigmund era também personagem.

Compreensivelmente inclinado para o Direito, é sob a influência de Goethe e de Darwin que finalmente se volta para os estudos de medicina. O contato com seus colegas na universidade é marcado pela já conhecida sensação de "não fazer parte da maioria", pela experiência do isolamento. Nesse contexto, o encontro com Ernst Brücke oferece ao jovem Freud a oportunidade de lançar-se, na realidade, em uma aventura com um grande homem, com um "modelo"2. Entre 1876 e 1882, ele inicia sob a direção de Brücke uma atividade promissora como anátomo-fisiologista do sistema nervoso. Sob o olhar entusiasmado de seu mestre, Freud se esmera como pesquisador, desenvolvendo sua capacidade de observação e sua técnica de dissecação do sistema nervoso de enguias. Incitado por Brücke, ele se lança no trabalho de sistematização e de teorização de suas observações, publicando cerca de vinte artigos sobre suas pesquisas.

Porém, em 1882, Freud decide abandonar a pesquisa em neurologia para dedicarse à clínica das doenças nervosas. A história oficial pontificia que esta guinada deveuse ao encontro entre Sigmund e Martha Bernays, ao seu enamoramento e ao projeto deste de construir com ela uma família, colocando em evidência sua necessidade e seu desejo de ganhar bem a vida. Freud chega a atribuir a Brücke o conselho para

2. S. Freud. "Um estudo autobiográfico" (1925). E.S.B., vol. XX. Rio de Janeiro: Imago, p. 20. 


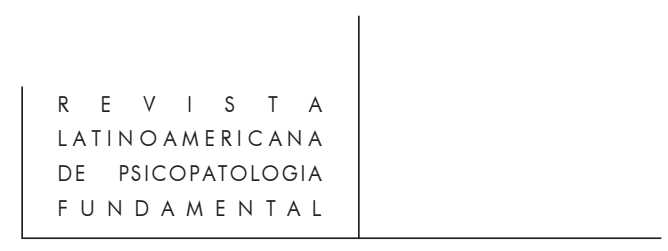

que abandonasse os estudos teóricos e que se candidatasse a uma função no Hospital Geral de Viena, em vista de sua "precária situação financeira". Determinado, ele concretiza sua decisão marcando-a, inclusive, com um gesto significativo: em 1885, às vésperas de sua partida para Paris, Freud queima todos seus escritos realizados até então.

Talvez, nesse momento, o leitor se pergunte: por que revisitar esses lugares tão conhecidos da saga freudiana? Que contribuição esse "retorno" às fontes pessoais da história da psicanálise poderia trazer para a compreensão de nosso tema?

O objetivo deste trabalho não é absolutamente trazer uma nova revelação sobre a historiografia da psicanálise ou sobre a rede de filiações do movimento psicanalítico, já bem descritas por diversos autores ${ }^{4}$.

O convite para percorrermos tais paragens visa sobretudo, num primeiro momento, resgatar de paisagens familiares a dimensão inexplorada, desconhecida e malformulada no início do percurso freudiano: a experiência da transferência.

Convite surpreendente, pois tendemos a pensar a transferência reconhecida como um elemento central da psicanálise, enquanto dinâmica essencial do trabalho psicanalítico ou, ainda, como conceito teórico. Porém, apesar disso, talvez ainda não tenhamos conseguido apreender completamente o alcance dessa experiência, tanto na história da psicanálise como na constituição e nas transformações da teoria e da psicopatologia psicanalíticas.

A insistência no termo experiência da transferência remete-se à dimensão do que nos é legado por W. Bion quando sugere um duplo movimento determinante de nossas existências: 1. "A emergência ou a derivação do pensamento a partir de uma experiência-fonte, originária e fundamental; 2 . $\mathrm{O}$ retorno da teoria às origens ou aos fundamentos da experiência adquirida pela personalidade ao longo de sua formação - de sua aprendizagem"5. Em seu espírito, essa concepção, a ser retomada na continuidade deste estudo, foi presente e determinante das criações freudianas, desde suas mais remotas origens.

Assim, este trabalho visa destacar a importância da sensibilidade de Freud a sua experiência transferencial - muito antes da formulação do conceito - com relação aos seus objetos de estudo e as suas relações pessoais e profissionais. Ele busca situar a experiência da transferência como verdadeiro operador que permitiu a Freud compreender e efetuar as teorizações e transformações que o conduziram de sua

3. Ibid., pp. 20-21.

4. P. Gay. Freud - Uma vida para nosso tempo. São Paulo: Companhia das Letras, 1991; W. Granoff. Filiations. Paris: Minuit, 1975; E. Roudinesco. La bataille de cent ans Histoire de la Psychanalyse en France I 1885-1939. Paris: Seuil, 1986; R. Mezan. Freud, pensador da cultura. São Paulo: Brasiliense, 1985.

5. W. Bion. Aux sources de l'expérience. Paris: PUF, 1991. 


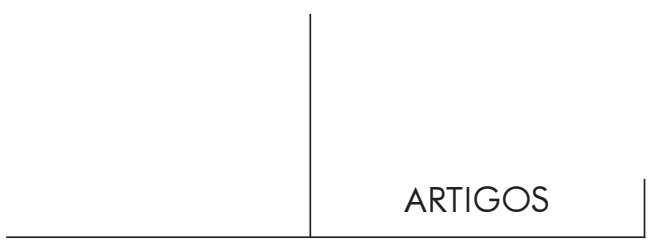

atividade inicial como anatomista ao desenvolvimento da psicanálise, enquanto método terapêutico e corpo teórico. Da mesma forma, ele se propõe a discutir essa função paradigmática da transferência como elemento incontornável da experiência passional constitutiva do conhecimento psicopatológico.

\section{"Sabes vencer, Aníbal, mas não sabes aproveitar de tua vitória"}

É este o veredito severo que recebe Aníbal de seu tenente Maharbal depois que o herói da Segunda Guerra Púnica desiste de avançar sobre Roma, após sua vitória em Cannes, em 216 A.C. Herói mítico, jurado por seu pai, Amílcar, de vingálo da vergonha que lhe fora imposta pelos romanos, Aníbal sempre foi, desde a juventude de Freud, um de seus mais constantes companheiros imaginários. A referência a sua identificação com o herói é recorrente, tendo ela sido inúmeras vezes associada às tentativas fracassadas de Freud de visitar Roma. Em que medida a ambivalência de Freud diante de suas conquistas ficou marcada pelas hesitações de seu herói?

Seguindo o "conselho" de Brücke, Freud se candidata e é aceito, em 1882, como assistente na clínica do professor H. Nothnagel, em Viena. Seis meses depois, é promovido a médico estagiário na clínica psiquiátrica de Meynert, cujo "trabalho e personalidade muito o haviam impressionado" durante seus estudos. Freud postula ao cargo de conferencista (Privat-Dozent), mas as resistências suscitadas pelo fato de ser judeu determinam que, apesar de apresentar todos os requisitos, sua nomeação só ocorra em 1885 após uma enérgica intervenção a seu favor conduzida por Brücke. É graças a ele, também, que Freud obtém a bolsa de estudos que lhe permite empreender sua viagem de estudos a Paris e Berlim, naquele mesmo ano.

Poderíamos nos ater à versão oficial dos fatos e, retrospectivamente, considerar que, afinal, todas essas etapas eram apenas passos inevitáveis para que Freud, como qualquer jovem médico, atingisse o reconhecimento profissional, principalmente considerando suas preocupações materiais com vistas a seu casamento com Martha. A descoberta da psicanálise seria, então, somente uma questão de um "tempo suficiente", necessário, para que nele se fizessem sentir os efeitos de um relato de caso que Breuer lhe fizera em novembro de 1882: o de Bertha Papenheim, ou Anna O.

É difícil, para nós, assim como o foi para Freud, como vemos em seu "Estudo autobiográfico", revisitar a pré-história da psicanálise sem estarmos impregnados pela história oficial desta ciência, e pela tendência de idealização de seu fundador.

A preocupação com os recursos materiais foi uma constante na história de Freud, tendo sido, sem dúvida, uma referência freqüente em sua vasta correspondência com Martha e, em menor grau, com vários outros correspondentes 


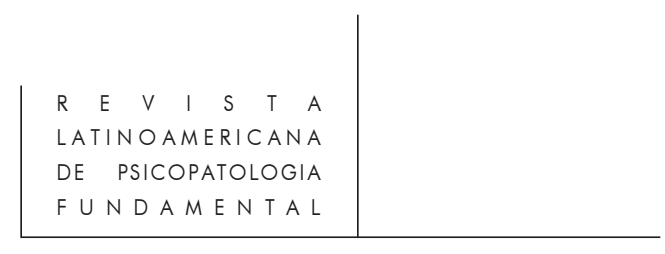

ao longo de sua vida. Porém, teria sido esse o único motivo para que Freud tivesse abandonado o lugar e o prestígio alcançado junto a Brücke, "por quem sentia a mais alta estima", renunciando à possibilidade que havia sido aventada de "preencher a vaga de professor assistente que viesse a ocorrer" em seu Laboratório ${ }^{6}$ ? Considerando o apoio que recebeu de seu mestre para sua nomeação como Dozent e para a atribuição de sua bolsa de estudos, não lhe teria sido difícil galgar os degraus da carreira acadêmica na cadeira por este dirigida.

Meynert também apreciava o trabalho de Freud. Ele lhe ofereceu seu laboratório mesmo quando este não trabalhava sob sua orientação, propondo-lhe "que se dedicasse inteiramente à anatomia do cérebro", prometendo-lhe, bem antes de 1885, passar-lhe suas atividades como conferencista por "sentir-se velho demais para lidar com métodos mais novos". Freud declina o convite, não se sentindo à altura da tarefa. Mais uma vez, assimilando do "ponto de vista material" a anatomia do cérebro à fisiologia, ele evoca considerações pecuniárias para justificar seu interesse pelas doenças nervosas. ${ }^{7}$

No relato de suas lembranças, Freud conta que em sua adolescência nunca sentira "qualquer predileção particular pela carreira de médico", sentindo-se mais atraído "para as preocupações humanas do que para os objetivos naturais". Nesse sentido, é curioso que tenha sido justamente na pesquisa anatômica e neurológica que ele tenha inicialmente tentado aproximar-se daquelas "preocupações". Apesar de sua sensação de isolamento, por suas capacidades e obstinação, Freud poderia ter se orientado diretamente ao seu campo de interesse para consegui-lo. Por que não o fez?

Sem dúvida, a acolhida de Brücke em muito determinou sua escolha. Porém, a história demonstrou que este era suficientemente aberto a ponto de apoiar Freud no momento que ele escolheu outros caminhos, diferentes do da pesquisa em laboratório. Podemos, então, considerar que, provavelmente, Freud efetivamente acreditou, no início, que a neurologia poderia trazer respostas para suas inquietações, e que, naquele momento, seu investimento nessa atividade era intenso e autêntico, como atestam sua produção científica e o reconhecimento de seu mestre. Uma constelação semelhante se configura quando ele é recebido e apoiado por Meynert, quando a precisão de seus diagnósticos é reconhecida por outros colegas vienenses e mesmo estrangeiros ${ }^{9}$, e quando, apesar dos obstáculos políticos e de preconceito,

6. S. Freud (1925). Op. cit., p. 20.

7. Ibid, p. 22.

8. Ibid, p. 18.

9. “... enquanto continuava a trabalhar como médico estagiário, publiquei grande número de observações clínicas sobre doenças orgânicas do sistema nervoso. Gradativamente familiarizei-me com o terreno; fui capaz de situar o local de uma lesão na medula oblonga de maneira tão exata 


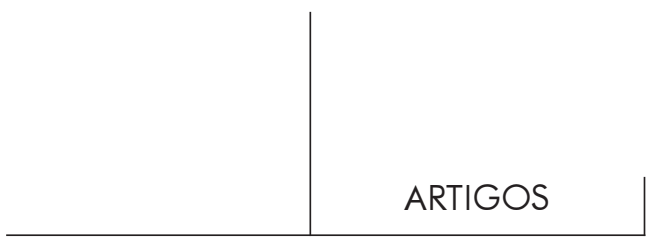

ele consegue por seus méritos atingir todos os graus da hierarquia hospitalar ao seu alcance na época.

Percebemos assim que com Brücke, Meynert, no Hospital Geral e nos círculos médicos de Viena, Freud passou a ser reconhecido e sobretudo acolhido, encontrando não apenas vias possíveis de saída para "seu isolamento", mas também para sua ascensão na hierarquia médica. Por que, então, as abandonou? Devemos aderir à teoria dos "motivos materiais"? Freud buscava como clínico de doenças nervosas apenas uma atividade que lhe possibilitasse uma maior tranqüilidade financeira?

Sem excluir a participação desses fatores, extensivamente destacados pelo próprio Freud, penso que, inclusive por respeito ao nosso método, deveríamos considerá-los também em sua função encobridora, buscando, para além de sua dimensão manifesta, seu sentido latente.

Todo estudante de medicina, psicologia, biologia e ciências afins trabalhou durante algum tempo em laboratórios experimentais de anatomia, biologia, ou neurologia. Frequientemente motivados em suas escolhas profissionais pelo interesse pela clínica e por "ajudar os outros", a grande maioria se pergunta, ao menos uma vez, senão várias, o que tais atividades laboratoriais "teriam a ver com o paciente". Imaginemos Freud, aluno brilhante, cônscio de suas capacidades e fortemente interessado em compreender a "natureza humana", inspirado pelos clássicos e pelos heróis da humanidade, sentado ao longo dos dias em salas azulejadas, cercado de peças anatômicas, animais e humanas, dissecando-as, estudando-as, classificandoas, tentando extrair das mesmas um nexo, um sentido. Responsável, cumpria suas tarefas com afinco, com qualidade, fazendo-se merecedor dos freqüentes elogios de seus superiores, gratificando-se com os mesmos. Mas o que sentia realmente com relação a tais atividades?

Que tipo de diálogo imaginário entabulava ele com seus heróis, com seus ideais, enquanto executava em sua bancada suas dissecações, quando redigia um relatório sobre suas descobertas? Que destino tinham, durante suas horas de trabalho, suas preocupações sociais e filosóficas, as reverberações de sua história infantil, as histórias relatadas por seu pai, seu interesse pela Bíblia, pela literatura? Como convocava diante dos corpos dissecados, diante da folha branca em que precisava descrevê-los, os fantasmas de Shakespeare, de Goethe, de Schiler, companheiros de longa data?

Sentindo-se inicialmente isolado, foi sem dúvida reconfortante, para Freud, encontrar no laboratório de fisiologia de Brücke "tranqüilidade e satisfação plena",

que o anatomista patológico não teve mais informação alguma a acrescentar, fui a primeira pessoa em Viena a encaminhar um caso para autópsia com um diagnóstico de polineurite aguda. (...) A fama de meus diagnósticos e de sua confirmação post-mortem trouxe-me uma afluência de médicos norte-americanos" Freud (1925), op. cit., p. 22. 


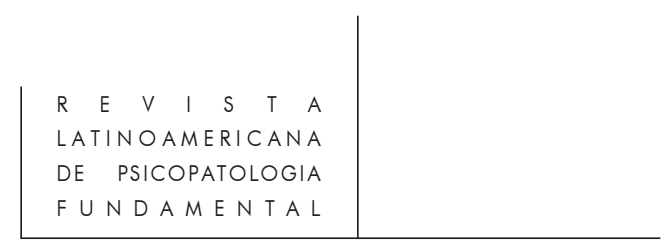

além de homens que pudesse "respeitar e tomar como (...) modelos"10. Porém não é difícil imaginar que ao longo do tempo Freud foi se interrogando sobre o sentido de sua atividade, confrontando-a com suas ambições, seus desejos, seus ideais. Ambivalente quanto a seus sentimentos, através da derivação para o estudo das doenças nervosas, Freud buscava aproximar-se de seus interesses. Continuava a sentir-se grato pela acolhida de Brücke. Sua preocupação com as questões pecuniárias se prestava como uma justificativa compreensível para não decepcionar aquele que o acolhera, ao contrário, suscitando, inclusive, seu encorajamento.

Apesar de seu sucesso junto a Brücke, Freud não se sentia ainda suficientemente seguro e preparado para seguir seu próprio caminho. Ele ainda necessitava de tutores, de modelos difíceis de serem encontrados no novo campo que escolhera ${ }^{11}$. Meynert e Nothnagel preencheram em parte esta função, sem suscitar em Freud o mesmo entusiasmo que Brücke. O convívio e as trocas com os colegas vienenses sempre foram descritos por Freud como marcados pela frieza e pela pouca receptividade, mesmo no tempo em que exercia como médico de doenças nervosas. Em parte, essas reações eram fruto da origem judaica de Freud, mas podemos também entender a sensação de Freud quanto a essas reações como uma insatisfação quanto ao seu próprio encontro com a realidade da clínica das doenças nervosas, e com as teorias que, na época, as sustentavam ${ }^{12}$. Em todos os textos em que relata sua história e a da Psicanálise, contrariamente à reserva que encobre o período de Brücke, é manifesta sua insatisfação quanto ao panorama que encontrou na prática com as doenças nervosas, bem como quanto aos seus colegas vienenses. Assim, não foi por acaso que, após o início de sua prática hospitalar, ele tenha começado a formular planos de buscar em outros horizontes respostas a perguntas que ele apenas pressentia, sem poder ainda formulá-las.

10. S. Freud (1925). Op. cit., p. 22.

11. "Havia naquela época, em Viena, poucos especialistas nesse ramo de medicina [doenças nervosas]. O material para seu estudo estava distribuído por grande número de diferentes departamentos do hospital, não havia oportunidade satisfatória para aprender a matéria, e se era forçado a ser professor de si mesmo", Ibid.

12. "Em certa ocasião, apresentei ao meu auditório um neurótico que sofria de dor de cabeça persistente como um caso de meningite crônica localizada; todos se levantaram imediatamente, revoltados, e me abandonaram, e minhas atividades prematuras como professor chegaram ao fim. À guisa de desculpas, posso acrescentar que isso aconteceu numa época em que maiores autoridades do que eu, em Viena, tinham o hábito de diagnosticar a neurastenia como tumor cerebral". Ibid., p. 23 


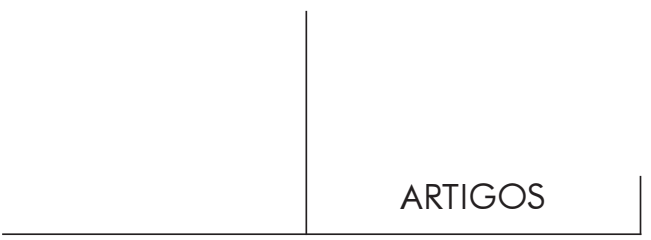

"Ao longe brilhava um grande nome..."

A estratégia era clara: “... primeiro obter uma designação como conferencista universitário [Dozent] sobre doenças nervosas, em Viena, e então dirigir-me a Paris para continuar meus estudos"13. Freud não se sentia ainda pronto para "ser professor de si mesmo", reconhecendo rapidamente que pouco podia esperar de seus mestres ou colegas vienenses. Reluzindo ao longe, o nome de Charcot oferecia-se como uma esperança de um novo aprendizado, mas, sobretudo, de um novo personagem, forte, carismático, no auge de sua glória e do reconhecimento por seus pares e por seu país. Para ele fora criada, pelo governo francês, a primeira cátedra mundial de clínica das doenças nervosas. A ele acorriam os grandes desse mundo. Seus honorários eram reconhecidamente um dos mais altos de Paris ${ }^{14}$. Diante dele se rendiam as vontades de pacientes e de discípulos, capturados pelo drama da cena hipnótica.

Porém, aquilo que Freud buscava em Charcot fosse, talvez, muito menos os segredos da glória e do poder do que uma presença suficientemente forte que permitisse a um jovem médico vienense de 29 anos compreender e superar os impasses criados por personagens para com os quais se sentia grato pela acolhida e pelo reconhecimento, mas que o induziram a se distanciar de sua vocação e de seus interesses pela essência do humano.

É curioso que pouco saibamos da prática freudiana pré-hipnótica como "médico de doenças nervosas". Não existem, até onde conhecemos, relatos de casos, ou artigos, onde Freud descreva as características de sua clínica. Quem eram seus pacientes? Quais as suas queixas, seus sintomas? Como os tratava? E. Jones, o autor que descreve com mais detalhes esse período da vida de Freud, indica minuciosamente as funções ocupadas por Freud no hospital, seus horários, o número de pacientes, mas nada menciona sobre as características de sua clínica ${ }^{15}$. Freud se refere apenas às terapêuticas clássicas ao seu dispor naquela época, prescrições de repousos em estações de águas, hidroterapia, e mesmo eletroterapia, com notável insatisfação. Por que Freud, recém-chegado dos laboratórios, sempre acostumado a registrar suas atividades, não se preocupou em divulgar sua experiência daquela época? Será que o fez? Será que os manuscritos sobre essas questões faziam parte dos documentos destruídos em 1885? Teriam permanecido inéditos e desconhecidos até hoje, nos Arquivos Freud, em Washington?

Qualquer que seja a resposta, devemos reconhecer nosso desconhecimento da clínica freudiana das doenças nervosas antes do advento da hipnose. Freud talvez

13. Ibid.

14. J.-B. Pontalis. "Entre Freud et Charcot", in Entre le rêve et la douleur. Paris: Gallimard, 1977.

15. E. Jones. The Life and Work of Sigmund Freud. New York: Penguin Books, 1977. 


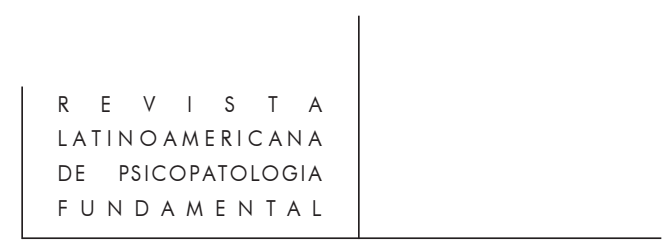

não a tenha considerado digna de registro ou comunicação, ou, pior, extremamente insatisfeito com a mesma, julgado-a merecedora de destruição.

Percebemos assim que para além do fascínio exercido pelo brilhante Charcot sobre o jovem Privatdozent, Paris também se oferecia a Freud como uma experiência voluntária de exílio. Um distanciamento necessário para elaborar suas decepções com os caminhos pelos quais se deixou conduzir pelo apego a seus mestres e com sua falta de interlocutores, para compreender o sentido de suas escolhas profissionais, tentar preencher o vazio experimentado em sua prática médica vienense, e, sobretudo, tentar compreender o sentido de ter que ser "mestre de si mesmo". Ao pousar suas malas naquele pequeno quarto de hotel do Quartier Latin, "entre o Panthéon e a Sorbonne", Freud descobre em sua bagagem o peso da ambivalência.

\section{O "fazedor de milagres"}

Nenhum outro homem gozaria, em toda a vida de Freud, do tratamento que este dispensou a Brücke. Apesar da escolha de outros caminhos, de seu completo afastamento da fisiologia e da neurologia, Freud nunca manifestou em sua obra qualquer reserva ou sentimento negativo com relação a seu primeiro mestre. Além dele, ninguém foi poupado. Mesmo os mais próximos companheiros ou discípulos foram alvo, em alguns momentos, da insatisfação e das críticas, pessoais ou teóricas, de Freud. As rupturas com alguns próximos como Fliess, Breuer, Tausk ou Jung, pacíficas ou violentas, mas sempre pesarosas, acompanharam-no até o fim de seus dias. Como se a natureza da relação e a história que vivera com Brücke, mas sobretudo a maneira como se separaram, tivessem proporcionado a Freud uma experiência única cuja gratidão para com a mesma preservasse tal idealização. Talvez, através dessa experiência, Freud possa ter compreendido, mais tarde, o poder da transferência em influir e, mesmo, modificar o desejo e os destinos de um homem. ${ }^{16}$

16. S. Freud. "A questão da análise leiga” (1927). ESB.,vol. XX. Rio de Janeiro: Imago.

"Após quarenta e um anos de atividade médica, meu autoconhecimento me diz que nunca fui realmente médico no sentido adequado. Tornei-me médico por ter sido compelido a desviar-me do meu propósito original; e o triunfo da minha vida está em eu haver, após uma viagem longa e indireta, encontrado meu caminho de volta à minha senda mais antiga. (...) Em minha juventude senti uma necessidade absorvente de compreender algo dos enigmas do mundo em que vivemos e talvez mesmo de contribuir com alguma coisa para a solução dos mesmos. O meio mais esperançoso de alcançar esse fim pareceu ser matricular-me na faculdade de medicina; no entanto, mesmo após isto, realizei experiências - sem êxito - com a zoologia e a química, até que afinal, sob a influência de Brücke, que teve mais influência sobre mim do que qualquer outra pessoa em toda minha vida, fixei-me em fisiologia (...). Naquela ocasião já havia sido aprovado em todos os meus exames médicos, mas não adquiri qualquer interesse por coisa 


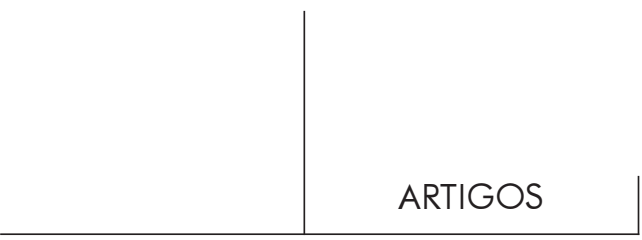

Apesar de sua reconhecida importância para Freud, Charcot não fica preservado de seus sentimentos contraditórios. Deixa-se encantar pelas maneiras do mestre, por seu poder de capturar seus ouvintes, pelos efeitos quase demiúrgicos que obtém em suas Leçons no hospital da Salpêtrière e em seu hôtel particulier. Ele se impressiona com suas contribuições acerca da histeria, atribuindo-lhe um lugar especial entre as doenças nervosas, acompanha pessoalmente suas demonstrações e experimentações com as pacientes, reconhece "a autenticidade das manifestações histéricas e de sua obediência a leis", a existência da histeria em homens, e a equivalência de "paralisias e contraturas histéricas produzidas por sugestão às mesmas características que os acessos espontâneos, que eram muitas vezes provocados traumaticamente" 17 . Freud aprende com ele a respeitar a clínica e a observação como soberanas com relação a qualquer teoria: “La théorie c'est bom, mais ça n'empêche pas d'exister", afirmava Charcot, "um mot que deixou indelével marca em [seu] espírito"18.

Porém, Freud também já não hesitava duvidar. Permitia-se ser tomado pelo ceticismo e pelo assombro diante das demonstrações do mestre. Ainda durante sua estadia em Paris, ele se ressentiu da pouca receptividade de Charcot ao caso de Anna O., cuja escuta da história clínica por Breuer tanto o havia entusiasmado ${ }^{19}$. Da mesma forma, Freud percebeu que sua hipótese "que na histeria as paralisias e anestesias das várias partes do corpo se acham demarcadas de acordo com a idéia popular dos seus limites e não em conformidade com fatos anatômicos" tampouco despertou em Charcot um "interesse especial”. Freud chegou mesmo a concluir que, diante de suas colocações, "foi fácil ver que na realidade [Charcot] não teve qualquer interesse especial em penetrar mais profundamente na psicologia das neuroses". Em 1925, ao mesmo tempo que enumera as contribuições do professor francês à sua

alguma que tivesse a ver com a medicina, até que o professor que eu tão profundamente respeitava advertiu-me de que, em vista das minhas circunstâncias materiais precárias, eu não poderia possivelmente seguir uma carreira teórica. Assim, passei da histologia do sistema nervoso para a neuropatologia e depois, incentivado por novas influências, comecei a interessar-me pelas neuroses. (...) Não é preciso que um físico tenha um paciente a fim de estudar as leis que regem os raios X. Mas o único tema da psicanálise são os processos mentais dos seres humanos e é somente nos seres humanos que ele pode ser estudado", (p. 287, sublinhado por $\operatorname{mim})$.

17. Freud (1925). Op. cit., p. 24.

18. Ibid.

19. “... tive a impressão de que isto [o caso Anna ] contribuía mais no sentido de uma compreensão das neuroses do que qualquer observação prévia. Tomei a determinação de informar Charcot a respeito dessas descobertas quando cheguei a Paris, e na realidade o fiz. Mas o grande homem não teve qualquer interesse pelo meu primeiro esboço do assunto, de modo que nunca mais voltei ao mesmo e deixei que fugisse de minha mente". Ibid., p. 32. 


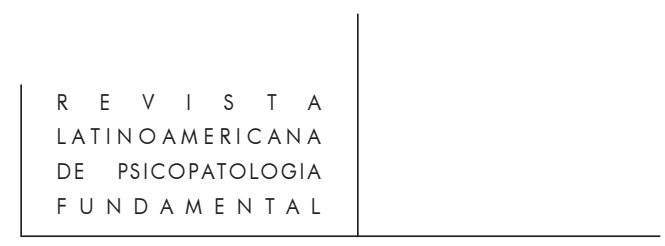

obra, ele afirma sem hesitar que "nem tudo o que Charcot nos ensinou naquela época é válido hoje: parte se tornou duvidoso, parte deixou definitivamente de resistir ao teste do tempo" 20 .

Apesar da diferença entre suas posições, o jovem Freud que encontrou o renomado Charcot não hesitou em manifestar suas próprias hipóteses, ousou compartilhar com o grande mestre de suas experiências, seus projetos, suas visões sobre a clínica. Ele se entregou à força de sua personalidade, reconhecendo que saía "de seus cursos como se saísse de Notre Dame, cheio de novas idéias sobre a perfeição", mas era capaz de preservar sua crítica com relação àquilo que vivia em torno do mestre: “... mas ele me esgota e, quando o deixo, não tenho mais nenhum desejo de dedicar-me a meus próprios trabalhos" ${ }^{21}$. Ele se dispôs a traduzir seus artigos para o alemão, participava da mise-en-scène e dos rituais das sessões de hipnotismo, mas ao mesmo tempo se questionava sobre a natureza do fenômeno produzido por Charcot com "suas" histéricas; reconhecia claramente a determinação dele em, apesar de tudo, como bom anatomista patológico, tentar conseguir, um dia, demonstrar as bases orgânicas da histeria. Que outros sentimentos se apossavam de Freud diante do espetáculo semanal oferecido por Charcot nos anfiteatros da Salpêtrière, diante da relação que se estabelecia entre este e suas pacientes e dos fenômenos que dela resultavam?

No início de 1886, Freud retorna a Viena se estabelecendo como "especialista de doenças nervosas". Trazia consigo a esperança de poder contar com os fenômenos da histeria para tentar compreender os relatos de Breuer sobre Anna O. que ainda reverberavam em seu espírito. Sentia-se encorajado a acrescentar a hipnose, bastante desprezada pela medicina germânica ${ }^{22}$, a seu arsenal terapêutico, ainda que se considerasse "um mau hipnotizador".

Freud não conseguia entender a natureza de suas dificuldades com relação à hipnose. Ele reconhecia que "havia algo de positivamente sedutor em trabalhar com o hipnotismo. Pela primeira vez existia um sentimento de haver superado o próprio desamparo, e era altamente lisonjeiro desfrutar da reputação de ser fazedor de milagres". Porém, seus resultados eram distantes daqueles que observara em Paris, e a "única" explicação que encontrava para tanto eram suas próprias dificuldades no "manejo da técnica". Instilava-se aqui a essência da contratransferência, mas em nenhum momento Freud pôde formular claramente que, talvez, tais dificuldades

20. Freud (1925). Op. cit., p. 24.

21. Carta a Martha, novembro de 1885.

22. “ $[\ldots]$ os professores de psiquiatria declararam por muito tempo que o hipnotismo era não somente fraudulento como também perigoso, e de considerarem os hipnotizadores com desprezo. Em Paris vira o hipnotismo usado livremente como um método para produzir sintomas em pacientes, então removendo-os novamente". Freud (1925). Op. cit., p. 28. 


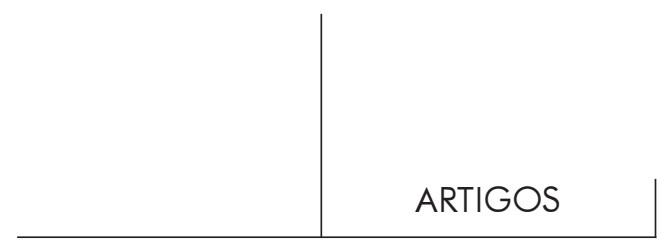

pudessem derivar dos efeitos de sua experiência diante das demonstrações e tratamentos das pacientes de Charcot, da utilização da hipnose como um recurso artificial para a produção de uma doença nervosa. Se Charcot lhe permitira resgatar sua liberdade de pensamento com relação a Brücke, Meynert, Nothnagel, como libertar-se, então, dos ruídos produzidos pelo encontro com Charcot?

Mais uma vez, a solução vinha "de longe". Freud descobre "uma escola em Nancy que fazia uso extenso e marcantemente bem-sucedido da sugestão, com ou sem hipnotismo, para fins terapêuticos". Uma escola que em muitas de suas concepções opunha-se frontalmente às posições da escola parisiense. Freud escolhe o conflito.

Com o intuito de "aperfeiçoar sua técnica hipnótica", ele passa várias semanas em Nancy, no verão de 1889, onde encontra Liébeault e Bernheim. Contrariamente a Charcot - o iluminado da Sapêltrière e do Boulevard Saint Germain - Freud "se comove" diante "do velho Liébeault" testemunhando "seu trabalho entre as mulheres e crianças pobres das classes trabalhadoras" 23 . Ele acompanhava também os trabalhos de Bernheim manifestando, com relação a eles, uma "profunda impressão" de que poderiam haver "poderosos processos mentais que, não obstante, permaneciam escondidos da consciência dos homens". Freud nunca se manifestara nesses termos com relação ao que observara com Charcot. Freud considerou as trocas com Bernheim estimulantes, comprometendo-se "a traduzir para o alemão umas duas obras sobre a sugestão e seus efeitos terapêuticos". Apesar de sua brevidade, passou a considerar seu périplo a Nancy como uma das viagens mais proveitosas de sua vida.

$\mathrm{O}$ embate entre Charcot e Bernheim representava mais do que um simples conflito entre dois mestres. Ele desvelava, diante de Freud, a encruzilhada a partir da qual se definiam dois caminhos diametralmente diferentes para a compreensão dos distúrbios nervosos e seu tratamento: de um lado, o modelo médico; as discussões espetaculares de caso em anfiteatro, as demonstrações de saber, o desfile do saber professoral, a passividade dos alunos. Charcot é um "visual", para quem a observação e a visibilidade da demonstração são fundamentais. Para ele, a hipnose é um instrumento para demonstrar a correção de suas hipóteses, considerando ainda que sua eficácia seria restrita unicamente aos quadros de histeria; de outro, Bernheim, um "intuitivo" que, com seus colegas de Nancy, fornecia evidências das relações que vinculam os fenômenos hipnóticos aos processos correntes da vida de vigília e do sono, trazendo "à luz as leis psicológicas que se aplicam a ambos os tipos de eventos" 24 . Para esses autores, a hipnose era antes de tudo um método terapêutico

23. Ibid., p. 29.

24. S. Freud. Prefácio à tradução de De la suggestion, de Bernheim (1888-9). ESB., vol. I. Rio de Janeiro: Imago. 


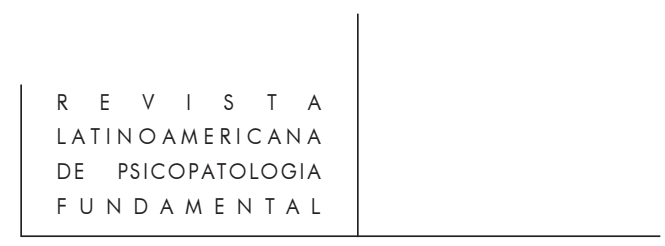

que evidenciava os fenômenos da sugestão presentes não apenas na histeria, e também observáveis em inúmeros outros tipos de tratamentos das doenças nervosas.

Diante de tal encruzilhada, Freud compreende o sentido do que experimentara junto a Libéault e Bernheim, e, por extensão, ressignifica seu aprendizado junto a Charcot. Entre a clínica do "visual" e a clínica da "intuição", Freud vislumbra a chave que poderia permitir-lhe navegar entre os "fenômenos conhecidos da vida psicológica normal e do sono", preparando o caminho para a clínica da escuta. Largando as amarras da medicina, ele pode, assim, lançar-se em sua jornada rumo à descoberta do inconsciente.

\section{Resumos}

Este trabajo tiene por objetivo iniciar la reflexión acerca de la función de la transferencia como operadora incontornable de la aprehensión y de la comprensión de la enfermedad, en su sentido más amplio, y de la psicopatología, en particular. Más que un "dispositivo" de la técnica psicoanalítica, la transferencia se constituye como un verdadero paradigma de la experiencia que revela la imbricación de lo sufrimiento de dos seres en relación. Es la elaboración de esta experiencia lo que permite la constitución del conocimiento psicopatológico.

Sobresalle aquí como, mucho antes de la formulación de este concepto, la sensibilidad de Freud con respecto a la suya experiencia transferencial, relativa a sus objetos de estudio y a sus relaciones personales y profesionales, se ha constituido como un vetor determinante de su trayecto de la neurología hasta la psicoanálisis, una dimensión poco considerada en la historia del psicoanálisis, así como en la del propio concepto de transferencia. La elaboración de esa experiencia fue un operador fundamental que ha permitido a Freud comprender y efectuar las teorizaciones y transformaciones que han instrumentado su pasaje de la pesquisa neuro-fisiológica y de la clínica médica clásica al desenvolvimiento del psicoanálisis, como método terapéutico y cuerpo teórico

Palabras llave: Transferencia, técnica psicoanalítica, historia del psicoanálisis, hipnosis

Cet article vise à amorcer la réflexion sur la fonction du transfert en tant qu'opérateur incontournable de l'appréhension et de la compréhension de la maladie, au sens le plus étendu, et de la psychopathologie en particulier. Beaucoup plus qu'un "dispositif" de la technique psychanalytique, le transfert se constitue comme un véritable paradigme de l'expérience révélatrice de l'intrication inévitable de la souffrance de deux êtres en relation. C'est l'élaboration de cette expérience qui permet la constitution de la connaissance psychopathologique.

Il s'agit ici de souligner comment, avant même la formulation de ce concept, la sensibilité de Freud à son expérience transférentielle, par rapport à ses objets d'étude 


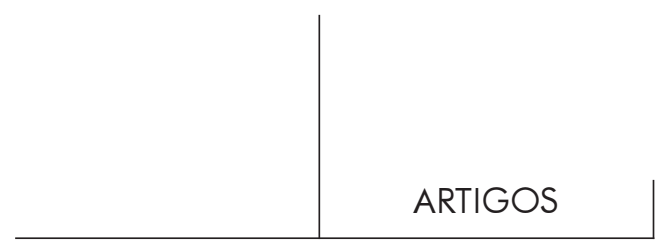

et à ses rapports personnels et professionnels, est devenue un vecteur déterminant de son parcours de la neurologie vers la psychanalyse. Cette dimension est bien peu prise en compte dans l'histoire de la psychanalyse aussi bien que dans celle du concept de transfert. L'élaboration de cette expérience a été un opérateur fondamental qui a permis à Freud d'effectuer les théorisations et transformations qui ont instrumenté son passage de la recherche neuro-physiologige et de la clinique médicale classique vers le développement de la psychanalyse, en tant que méthode thérapeutique et corpus théorique.

Mots clés: Transfert, technique psychanalytique, histoire de la psychanalyse, hypnose

This paper aims to stimulate the reasoning about the transfer as fundamental concept for the seizure and the understanding of the illness, in its spreader sense, and of the psychopathology particularly. Much more than a "device" of the psychoanalytical technique, the transfer constitutes itself as a real paradigm for the revealing experience of the unavoidable fusion of the relationship of two humans beings' suffering. It's the elaboration of this experience that permits the creation of the psychopathological knowledge.

It is here about underlining how, even before the formulation of this concept, Freud's sensitivity to his transferential experience, in relation to his study objects and to his personal and professional relationships, became an essential carrier that enabled his passage from the neurology toward the psychoanalysis. This dimension is very little taken in account in the history of the psychoanalysis as well as in that one of the transfer concept. The elaboration of this experience was a fundamental element that allowed Freud to theorize and transform his reasoning that brought about his passage from the neuro-physiologic research and the classical internal medicine toward the development of the psychoanalysis, as a therapeutic method and a theoretical corpus.

Key words: Transference, psychoanalytical technique, psychoanalytical history, hypnosis. 